\title{
An Iatrogenic Iliocaval Fistula after a Lumbar Disc Herniation Surgery: Case Study
}

\author{
Elfatemi B*, Bakkali T, Tijani Y, Khloufi S, Sefiani Y, Lekehel B, Mesnaoui A
}

${ }^{1}$ Vascular Surgery Service ibn Sina Hospital Rabat

${ }^{2}$ Vascular surgery service rene dubos hospital pontoise Paris

*Corresponding author: Elfatemi Bouthainah

\section{Abstract}

An observation of an iliocaval fistula with right cardiac insufficiency was reported 8 years after surgery for a lumbar posterior disc herniation treated by endovascular stent grafting by femoral placement. The postoperative outcomes were favorable. The vascular complications of lumbar disc surgery are uncommon (about $0.04 \%$ of discectomies) but are very severe. The most frequent complications are arteriovenous ilio-venous fistulas between the primary right iliac artery and the inferior vena cava. They are enhanced by the close anatomical relationship between the last lumbar vertebrae and the retroperitoneal vessels and the degenerative lesions of the anterior vertebral ligament making its perforation easier during discectomy. Their treatment has become increasingly simple with the progress and innovation of endovascular techniques.

Keywords: Iliocaval fistula - lumbar disc herniation - endoprosthetic - discectomy - right cardiac insufficiency.

Copyright @ 2020: This is an open-access article distributed under the terms of the Creative Commons Attribution license which permits unrestricted use, distribution, and reproduction in any medium for non-commercial use (NonCommercial, or CC-BY-NC) provided the original author and source are credited.

\section{INTRODUCTION}

Vascular complications of herniated disc surgery are very rare, but dramatic when it comes to haemorrhagic forms with ischemia of the lower limb. Iliocaval fistulas are the most frequent and don't show any signs of right heart failure during the postoperative period. The treatment of this kind of fistula is nowadays easier thanks to the progress of endovascular procedures. Their severity is related to the extent of the heart failure. We report the observation of a 54-year-old patient which overcame a disc herniation surgery 8 years ago with an iliocaval fistula diagnosed through a CT angiography and treated endovascularly.

\section{Observation}

Mrs. H.F, 54 years old, overcame a surgery in 2004 for herniated disc L4-L5 in Casablanca by posterior approach. The postoperative outcomes were marked by the appearance of oedemas of lower limbs, progressively worsening dyspnea and signs of predominantly right heart failure: hepatomegaly, turgidity of the jugular veins as well as a pericardial effusion for which she underwent decompressive cardiac surgery.

According to the altered general condition of the patient, a trans-thoracic scan was performed, which revealed: hyper cardiac output, dilated inferior vena cava and significant tricuspid insufficiency + AHTP. The right cavities were moderately dilated with reflux in the supra-hepatic veins.

An echodoppler scan of the lower limbs was carried out and revealed the presence of an extremely large-flow iliocaval arteriovenous fistula between the right iliac artery and the inferior vena cava measuring $2 \mathrm{~cm}$ wide, which was confirmed by CT angiography. (Figure 1).

The patient was operated in September 2012 over-went a right iliac stent graft through the femoral route. During the procedure a cardiac echo endoscopic monitoring was performed. A mini approach of the right Scarpa allowing to put the common femoral artery on the lake. During the approach, the arch of the long saphenous vein was extremely voluminous and measured more than one centimeter, which is perfectly explainable in the context of venous hypertension linked to the fistula. Visualization of this absolutely massive fistula, no contrast product was used to opacify the iliac artery downstream of the fistula, all the contrast product passes directly into this full-channel fistula in the vena cava (Figure 2). This vena cava is very large, measuring approximately $4 \mathrm{~cm}$. Placement of the V12 ATRIUM stent graft diameter 12, length 40 
and dilation of the stent graft with a balloon. Control shows a persistent leak (Figure 3), a second prosthesis is repositioned towards the iliac bifurcation ATRIUM V12 diameter 11 after placement of the latter, persistence of a very small late leak, re-ballooning at a pressure of 12 ATM and complete disappearance of the leak (Figure 4). The after-effects of the operation were simple.
Post-operative outcomes in October 2012: return to normal cardiac output at $5.2 \mathrm{l} / \mathrm{min}$, relative septal hypokinesia in a context of major correction of cardiac output and less dilated right heart chambers.

A follow-up angioscan two years later showed definitive exclusion of the fistula with a reduction in the calibre of the inferior vena cava and the supra-hepatic veins, and no endoleak (Figure 5).

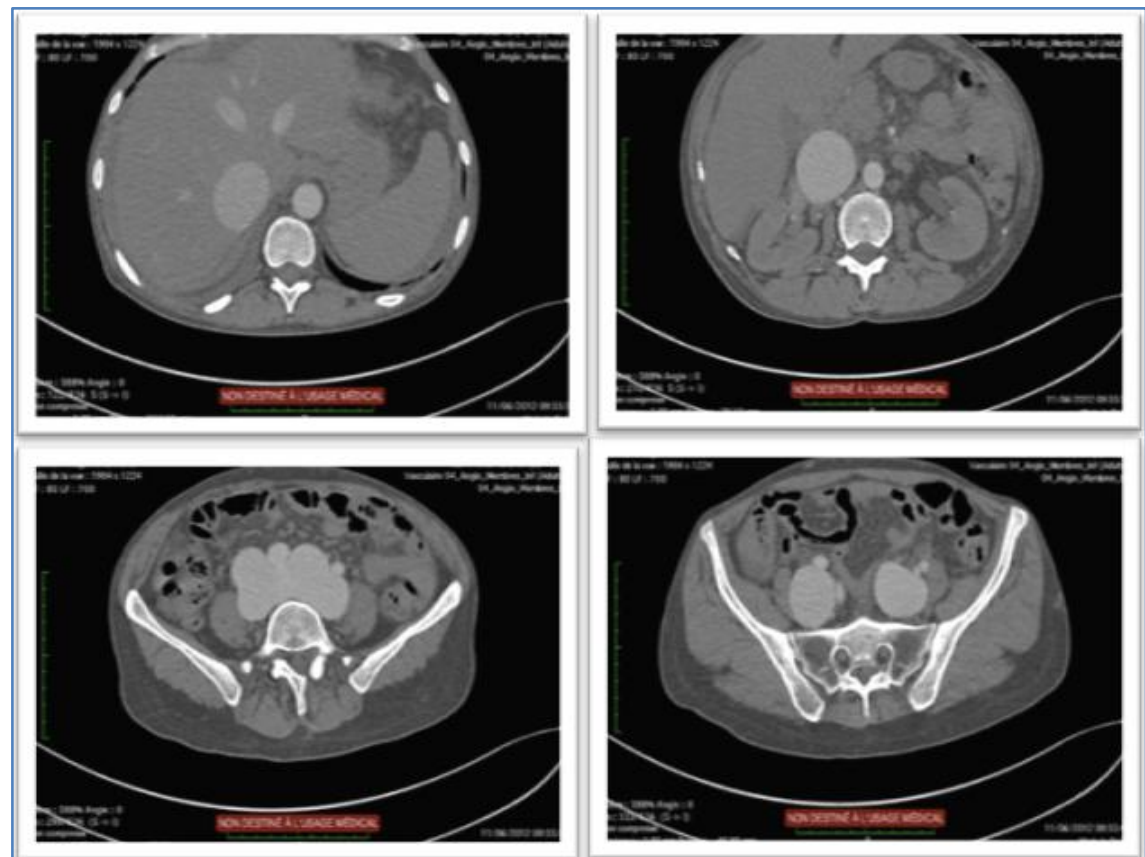

Fig-1: CT angiography of the abdominal aorta at arterial time showing the opacification of the inferior vena cava and the hepatic veins which are very large with an ilio vellum fistula of approximately $2 \mathrm{~cm}$ wide

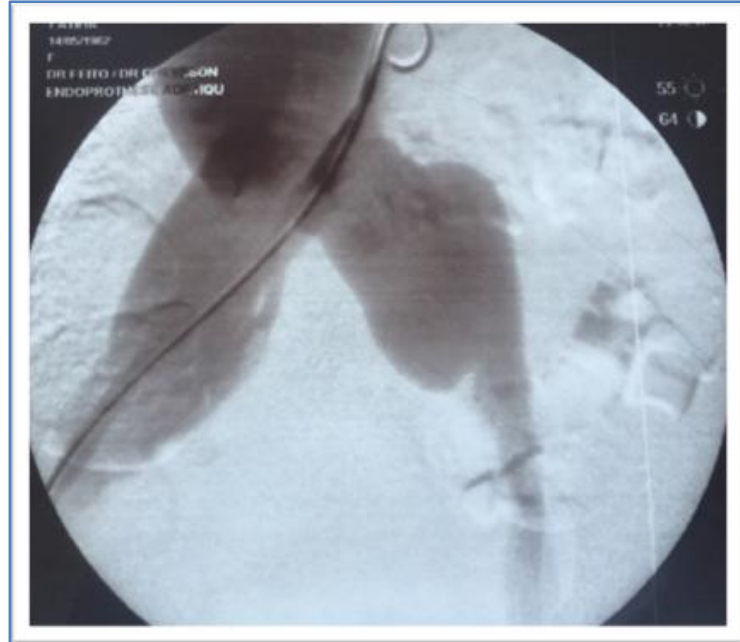

Fig-2: Per operative angiographic image showing the lack of opacification of the aorta and iliac artery due to the ilio-vascular arteriovenous shunt

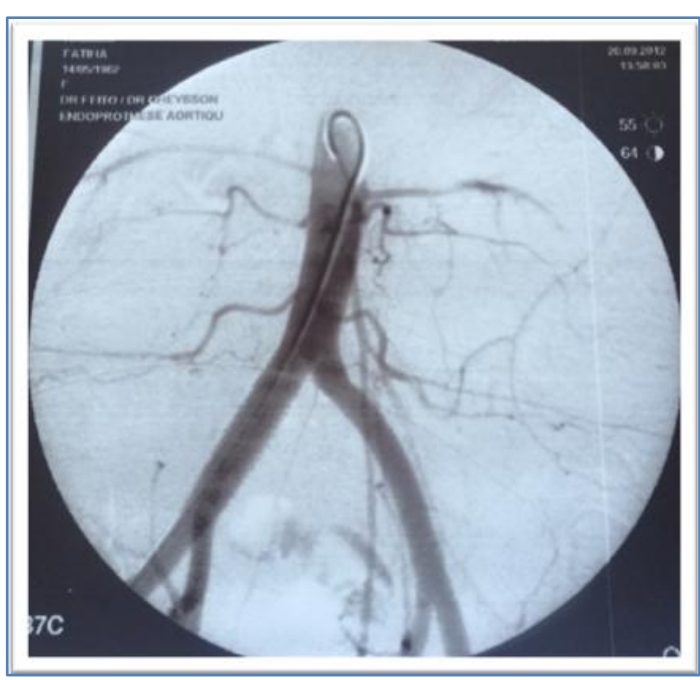

Fig-3: Persistence of a leak after release of the first stent at the level of the primary iliac artery 


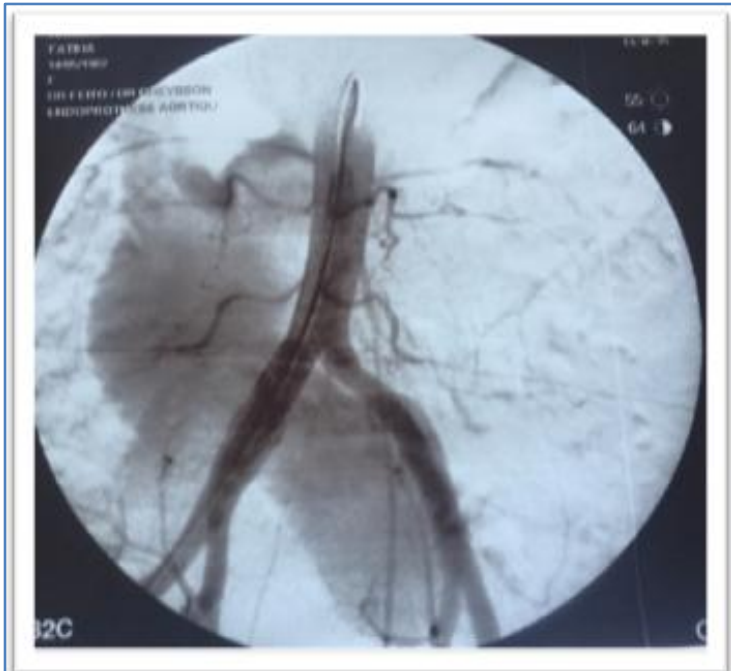

Fig-4: Definitive exclusion of the ilio cave fistula with satisfactory angiographic control
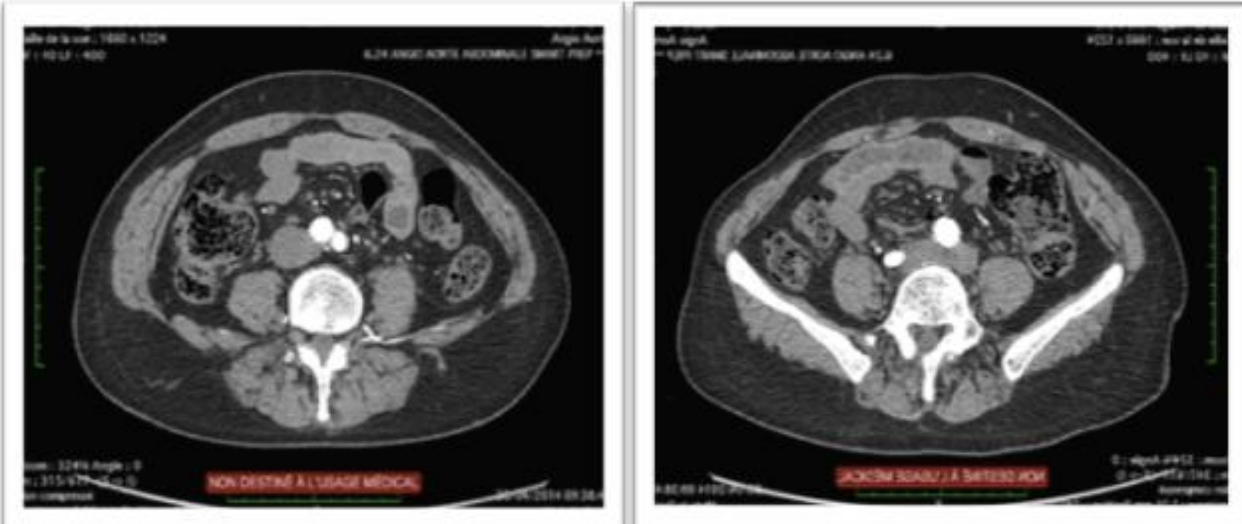

Fig-5: Two-year follow-up CT angiography: permeable stent with no endoleak

\section{DISCUSSION}

These are the vascular lesions most frequently observed as a complication of disc surgery. They happen in about two thirds of cases: $69 \%$ for Birkeland and Taylor [1], 63.9\% for Pillet et al. [2], 66\% for Papadoulas et al. [14].

They are usually diagnosed only secondarily or late. Of the 73 cases of arteriovenous fistulas collected by Jarstfer and Rich [3], only $8.5 \%$ of them are recognized within the first 24 hours, $31.9 \%$ between 24 hours and a week, and a total of $55.3 \%$ within a month after the disc operation. In the Papadoulas et al. series of 66 arteriovenous fistulas, only $45 \%$ are recognized within one month of discectomy. Khargi et al. [4] report the case of a patient who was not diagnosed until 33 years after the causal procedure; in our patient the diagnosis was made 4 years after disc surgery.

The usual clinical picture is that of heart failure with dyspnea, hepatomegaly, oedema of the lower limbs, cardiomegaly. The location of this fistula on large vessels explains the possible acute onset of heart failure within a few days or even hours: Wajszczuk et al. [5] described a patient in whom the signs of heart failure appeared as early as 16 hours after the disc surgery and Lesoin et al. [6] a case of fatal heart failure on the sixth day postoperatively. Such a development is possible because of the usually very high flow rate of these fistulas: one patient of Jarstfer and Rich [3] had a flow rate of $19.81 /$ minute. The clinical signs of this heart failure are the presence of a continuous abdominal murmur sound, often intense and sometimes perceived by the patient himself, accompanied by a thrill; finally, the heart failure regresses after removal of the fistula. Oftenly, an incomplete clinical examination, in particular without auscultation of the abdomen, is responsible of the nondiagnostic of arteriovenous fistula for a prolonged period of time. Locally, the fistula is constantly accompanied by venous dilatation and aneurysmal dilatation of the associated artery, these dilatations being all the more marked the longer the duration of evolution; they sometimes reach a huge volume [7].

Rarely, arteriovenous fistulas result in signs of venous overload or venous thrombosis of the lower limbs without associated heart failure, the development of a stenosis or iliac venous thrombosis or especially venous cava downstream of the fistula slowing down the cardiac overload $[8,9]$. 
CT angiography should be carried-out as the first examination when there is a clinical suspicion of arteriovenous fistula [10, 11]. It visualizes the lesion and specifies its location and extension. Arteriography is useful when endovascular treatment is being considered.

The severity of arteriovenous fistulas is less than that of haemorrhagic forms: Boyd and Fahra [12] and Hildreth and Turcke [13] studies report a mortality rate of $8 \%$ out of the 25 and 50 cases they have respectively collected and Papadoulas et al. [14] a rate of $5 \%$ out of 66 cases. It is, in fact, the severity of the cardiac disease that conditions mortality.

Difficult exposure of the abdomino-pelvic vessels and venous hyper-pressure explain why surgical repair of these lesions is associated with a high rate of bleeding and mortality $[15,16]$. Endovascular treatment is therefore a newer and less invasive alternative. It is based on treatment with covered stents to end the communication while preserving arterial and venous permeability $[15,28]$. It can only be performed in cases of stable hemodynamic status and favorable anatomical conditions, and is also indicated in patients at high surgical risk [17]. Concerning the endovascular treatment chosen in our patient. It was decided to place a stent only at the level of the primary iliac artery, but due to the persistence of a small leak, a second covered stent was dropped, protruding at the level of the aorta, which was well compacted at the origin of the iliac artery. The origin of the hypogastric artery remained free. These precautions allowed us to avoid endoleakage at the proximal stent attachment site. This type of Type 1A endoleak, similar to aortic stents, is exceptionally reported for isolated aneurysms of the iliac arteries. If the leak is significant, it would require the placement of a stent extension, as in our patient's case, although surgical conversion would be required if the endovascular procedure is not possible. Type 2 endoleaks occurring from an arterial branch covered by the stent graft. In this case the internal iliac artery, are the most common. Prior embolization of the internal iliac artery is required prior to stent graft delivery. Type 3 and 4 endoleaks are extremely rare. Moderate endoleaks detected by CT scan should be monitored regularly [19]. The evolution of the cases reported in the literature is characterized by the disappearance of physical signs of heart failure after closure of the shunt as in our patient [20]. Furthermore, endovascular treatment remains associated with a low mortality and bleeding rate compared to open surgery.

In the literature, covered stents have been placed in about ten patients [21-27]. Two failures cases were reported $[43,49]$ and required surgery to achieve complete closure of the arteriovenous fistula. The advantages of endovascular techniques are their benign nature, which allows their use even in cases of severe heart failure, and shorten the hospital stay.
Complications are rare and predominantly due to the occurrence of endoleak, rarely thrombosis. In the literature only one case of thrombosis of aortobiiliac stent graft Anaconda type has been reported surgically treated: bi-iliac bypass surgery, the patient over-went a second intervention for recurrence of herniated disc and the authors suppose that the position of the ventral decubitus could be incriminated in the occurrence of thrombosis [28].

\section{CONCLUSION}

Vascular complications from spinal surgery are very rare and arteriovenous fistulas are the most common of them. Endovascular treatment has increasingly facilitated their management. It avoids all the difficulties and complications related to any open surgery, and particularly for severe forms with visible benefits at short and long-term.

\section{REFERENCES}

1. Birkeland IW, Taylor TKF. Major vascular injuries in lumbar disc surgery J. Bone Joint Surg. 1969; 51 B: 4-19

2. Pillet JC, Pillet MC, Braesco J, Thomas E, Bezon E, Mondine PH. Complications vasculaires de la chirurgie discale lombaire. À propos de deux cas et d'une revue de littérature de 122 cas. J. Mal. Vasc. 1995; 20: 219-223

3. Jarstfer B.S, Rich N.M. The challenge of arteriovenous fistula formation following disc surgery: a collective review J. Trauma 1976; 16: 726-733

4. Khargi K, Bemelman W.A, Voorwinde A, Keeman J.N. Aortocaval fistulas Neth. J. Surg. 1991; 43: 1-5

5. Wajszczuk WJ, Mowry FM, Whitcomb JG. Arteriovenous fistula - a complication of surgery of intervertebral discRocky Mt. Med. J. 1969; 66: 37 39

6. Lesoin F, Warembourg H, Asseman P. Fatal congestive heart failure associated with an iatrogenic caval aortic fistula following surgical removal of a herniated intervertebral disc Surg. Neurol. 1984; 22: 532

7. Harbison S.P. Major vascular complications of intervertebral disk surgery Ann. Surg. 1954; 140: 342-348.

8. Fallahnejad M, Boland B.J, Chait A. Aortoiliac arteriovenous fistula simulating iliac vein thrombosis following intervertebral surgery Can. J. Surg. 1983; 26: 366-367

9. Johnsrude I.S, Bogey W.M, Tripp M.D. Postlaminectomy arteriovenous fistula masked by stenosis of the inferior vena cava Cardiovasc. Intervent. Radiol. 1994; 17: 336-338

10. Canaud L, Hireche K, Joyeux F, D'Annoville T, Berthet JP, Marty-Ané C. Endovascular repair of aorto-iliac artery injuries after lumbar-spine surgery. Eur J Vasc Endovasc Surg. 2011;42:16771. 
11. Lee KH, Park JH, Chung JW, Han JK, shin SJ, Kang HS. Vascular complications in lumbar spinal surgery: percutaneous endovascular treatment. Cardiovasc Intervent Radiol. 2000; 23:65-9.

12. Boyd DP, Farha G. Arteriovenous fistula and isolated vascular injuries secondary to intervertebral disk surgery: report of four cases and review of the literature Ann. Surg. 1965; 161: 524531

13. Hildreth DH, Turcke DA. Postlaminectomy arteriovenous fistula Surgery. 1977; 81: 512-520

14. Papadoulas S, Konstantinou D, Kourea HP, Kritikos N, Haftouras N, Tsolakis JA. Vascular injury complicating lumbar disc surgery. A systematic review Eur. J. Vasc. Endovasc. Surg. 2002; 24: 189-195

15. Queiroz AB, Mulatti GC, Aun R, Valentim LA, Puech-Leão P. Endovascular repair of a traumatic arteriovenous fistula involving the iliac bifurcation using an iliac branch device. J Vasc Surg. 2012; 55:1474-6. 1

16. Franzini M, Altana P, Annessi V, Lodini V. Iatrogenic vascular injuries following lumbar disc surgery. Case report and review of the literature. J Cardio vasc Surg (Torino). 1987;28:727-30.

17. Beecher S, Alawy M, Elbakar A, Tubassam M. Incidental discovery of a long standing arteriovenous fistula after thrombectomy for acute lower limb ischaemia. Int J Sur case Rep. 2014; 5:1031-4.

18. Ben Jemaaa H, Maalejb A, Lazzezb K, Jemala H, Karraya S, Ben Mahfoudh K. Endovascular repair of iliocaval arteriovenous fistula complicating lumbar disc surgery.JMV-576

19. Jeuriëns- van de Ven SA, Schouten van der Velden AP, Schultze Kool LJ, van der Vliet JA, Berger P. Persisting iliaco- caval fistula after EVAR maintained by a type II endoleak. Ann Vasc Surg. $2011 ; 25,1142$ e7-e9.
20. El hammiri A, Jarmoune YK, Benhaourech S, Allouch M, Noureddine M, Habbal R. Cardiac consequence of misdiagnosed vascular complication of spinal lumbar surgery: 6 years of diagnosis delay. J Cardiol Cases 2015

21. Buerger T, Meyer T, Tautenhahn J, Halloul Z, Fahlke J. Percutaneous treatment of rare iatrogenic arteriovenous fistulas of the lower limbs Int. Surg. 199 8; 83: 198-201

22. Lee KH, Park JH, Chung JW, Han JK, Shin SJ, Kang H.S. Vascular complications in lumbar spinal surgery: percutaneous endovascular treatment Cardiovasc. Intervent. Radiol. 2000; 23: 65-69

23. Wang EA, Lee MH, Wang MC, Lee HY. Iatrogenic left iliac-caval fistula: imaging and endovascular treatment AJR Am. J. Roentgenol. 2004; 183: 1032-1034

24. Brunkwall J, Lindblad B, Ivancev K, Emtersjö G, Risberg B. Iatrogenic AV-fistula treated by a graftcovered self-expandable stent Eur. J. Vasc. Endovasc. Surg. 1996; 12: 243-245

25. Kwon TW, Sung KB, Cho Y.P. Kim DK, Ko GY, Cho YP. Ann. Chir. Vasc. 2003; 17: 438-444

26. McCarter DHA, Johnstone RD, McInnes GC, Reid DB, Pollock JG, Reid AW. Iliac arteriovenous fistula following lumbar disc surgery treated by percutaneous endoluminal stent grafting $\mathrm{Br}$. J. Surg. 1996; 83: 796-797

27. Ventura M, Rivellini C, Saracino G, Mastromarino A, Spartera C, Zannetti S. Endovascular treatment of a postlaminectomy arteriovenous fistula. A case report J. Cardiovasc. Surg. (Torino). 2002; 43: 523-526

28. De Magistris L, Arru L, Verbeeck N, Pillet J.C. Thrombosis of an aorto-iliac stent graft used for treating an iliocaval arteriovenous fistula following lumbar disc surgery. Journal des Maladies Vasculaires. 2013;38, 271-275. 